\title{
Influenza Chimeric Protein (3M2e-3HA2- NP) Adjuvanted with PGA/Alum Confers Cross-Protection against Heterologous Influenza A Viruses
}

\author{
Chaewon Kwak ${ }^{1,2^{\dagger}}$, Quyen Thi Nguyen ${ }^{1,2^{\dagger}}$, Jaemoo Kim ${ }^{1,2}$, Tae-Hwan Kim ${ }^{1}$, and Haryoung Poo ${ }^{1,2 *}$ \\ ${ }^{1}$ Infectious Disease Research Center, Korea Research Institute of Bioscience and Biotechnology (KRIBB), Daejeon \\ 34141, Republic of Korea \\ ${ }^{2}$ Department of Biosystems and Bioengineering, KRIBB School of Biotechnology, University of Science and \\ Technology (UST), Daejeon 34113, Republic of Korea
}

\begin{abstract}
Vaccination is the most effective way to prevent influenza virus infections. However, conventional vaccines based on hemagglutinin (HA) have to be annually updated because the HA of influenza viruses constantly mutates. In this study, we produced a 3M2e-3HA2-NP chimeric protein as a vaccine antigen candidate using an Escherichia coli expression system. The vaccination of chimeric protein $(15 \mu \mathrm{g})$ conferred complete protection against A/Puerto Rico/8/1934 (H1N1; PR8) in mice. It strongly induced influenza virus-specific antibody responses, cytotoxic T lymphocyte activity, and antibody-dependent cellular cytotoxicity. To spare the dose and enhance the cross-reactivity of the chimeric, we used a complex of poly- $\gamma$-glutamic acid and alum (PGA/alum) as an adjuvant. PGA/alumadjuvanted, low-dose chimeric protein ( 1 or $5 \mu \mathrm{g}$ ) exhibited higher cross-protective effects against influenza A viruses (PR8, CA04, and H3N2) compared with those of chimeric alone or alumadjuvanted proteins in vaccinated mice. Moreover, the depletion of $\mathrm{CD4}^{+} \mathrm{T}, \mathrm{CD8}^{+} \mathrm{T}$, and NK cells reduced the survival rate and efficacy of the PGA/alum-adjuvanted chimeric protein. Collectively, the vaccination of PGA/alum-adjuvanted chimeric protein induced strong protection efficacy against homologous and heterologous influenza viruses in mice, which suggests that it may be a promising universal influenza vaccine candidate.
\end{abstract}

Keywords: Influenza virus, universal vaccine, adjuvant, cross-reactivity

Received: November 18, 2020 Accepted:December 1, 2020

First published online: December 2, 2020

*Corresponding author Phone: $+82-42-860-4157$ Fax: +82-42-879-8498 E-mail: haryoung@kribb.re.kr

These authors contributed equally to this work.

Supplementary data for this paper are available on-line only at http://jmb.or.kr.

pISSN 1017-7825 eISSN 1738-8872

Copyright(C) 2021 by The Korean Society for Microbiology and Biotechnology

\section{Introduction}

Influenza viruses are single-stranded RNA viruses that can be classified into subtypes based on the hemagglutinin (HA) and neuraminidase (NA) of their surface proteins [1]. They belong to the Orthomyxoviridae family and undergo highly variable antigenic mutations similar to those of other RNA viruses $[2,3]$. Influenza viruses cause respiratory diseases in humans and cause between 290,000 and 650,000 deaths every year [4]. The main host that spreads influenza viruses is wild birds, which are primary reservoirs for most influenza A viruses [5]. At present, vaccination is the most effective method available for preventing influenza virus spread and infections $[6,7]$.

Current influenza virus vaccines are predicted and composed of influenza A ( $\mathrm{H} 1 \mathrm{~N} 1$ and $\mathrm{H} 3 \mathrm{~N} 2)$ and influenza B viruses. They are highly strain- and HA-specific, but do not induce cross-reactive antibodies $[8,9]$. The drawback of forecasted influenza virus vaccines is weak immune responses against antigenic variants of influenza viruses [10] because the vaccines could be mismatched with circulating influenza viruses due to rapid antigenic shift and drift in these viruses $[11,12]$. Thus, annual vaccination is necessary, but much effort is required to manufacture influenza virus vaccines. Moreover, influenza viruses have produced four pandemics within the past 100 years; the Spanish flu (1918), Asian flu (1957), Hong Kong flu (1968), and swine flu (2009), and the Spanish flu caused approximately 50 million deaths in 1918 [13]. Because of these outbreaks and risks, many researchers have tried to develop a universal influenza vaccine (UIV) to induce broad protections against diverse influenza viruses [14-18].

To date, the HA2 (stem region), extracellular domain of matrix protein 2 (M2e), and nucleoprotein (NP) are considered the major targets of UIV $[15,19,20]$. HA1 (head region) has a critical role in binding to receptors leading to entry into the host cells $[21,22]$. On account of this, it has been used as an essential element to develop commercial influenza vaccines, but many studies reported the importance of HA2-specific antibodies providing heterosubtypic protection [23-25], and researchers focused on a conserved region of HA2 across influenza A subtypes [26]. In particular, a non-neutralizing antibody induced by HA2 could promote antibody-dependent 
cellular cytotoxicity (ADCC) related to cross-protection against influenza viruses [27]. However, immune responses generated against the HA2 are only effective to confer protection against a low dose of heterologous influenza virus infections and are insufficient against a high dose of heterosubtypic influenza viruses [28]. Thus, many efforts have been made to develop another UIV target candidate such as M2 including M2e, a wellconserved protein in influenza viruses [29]. The M2 protein as a vaccine antigen induces a high level of M2specific antibodies and confers protection against both homologous and heterologous influenza viruses [30, 31]. Moreover, M2 contains B- and T-cell epitopes that promote humoral and cellular immune responses in vaccinated mice [32-36]. Nevertheless, M2e-specific antibodies showed the limitations of neutralization and prevention of influenza virus infections, and they are mainly responsible for virus clearance following infections [28, 37].

Accumulated reports demonstrated that cytotoxic T lymphocytes (CTL) are critical for cross-protection against influenza viruses $[38,39]$, and nucleoprotein (NP), a highly conserved region of the influenza virus, contains epitopes that induce $\mathrm{CD} 8^{+} \mathrm{T}$ cell responses that kill virus-infected cells $[40,41]$. The vaccination of mice with $\mathrm{NP}$ antigen induces $\mathrm{CD}^{+} \mathrm{T}$ cell responses, leading to marked cross-protection against lethal challenges of heterologous influenza viruses [41-43]. However, none of these conserved antigens has been licensed as a UIV so far despite numerous trials. Thus, the improvement of vaccine formulation is necessary to enhance vaccine efficacy and cross-protection against divergent influenza viruses.

Recently, numerous efforts have been made to generate a combination of recombinant proteins (HA2 and M2e) and Toll-like receptor ligand (flagellin)-fused recombinant protein, and virus-like particles to develop a new universal influenza vaccine antigen. It has been reported that recombinant proteins (HA2 and M2e) and flagellinfused protein targeting M2e and HA2 could induce the cross-reactivity against heterologous influenza viruses [44-46]. However, the heterosubtypic cross-reactivity of adjuvanted chimeric protein (3M2e-3HA2-NP) has never been investigated.

The use of vaccine adjuvants is also a promising strategy to enhance cross-protection against antigenically diverse influenza viruses [28]. A previous report demonstrated that the use of a complex of poly- $\gamma$-glutamic acid $(\gamma$-PGA) and alum (PGA/alum) induced cross-protective immunity through a pandemic H1N1 vaccine against heterologous viruses in mice [47]. In this study, we report that vaccination with a high dose of a $3 \mathrm{M} 2 \mathrm{e}-3 \mathrm{HA} 2-\mathrm{NP}$ chimeric protein $(15 \mu \mathrm{g})$ provided marked protection against A/Puerto Rico/8/1934 (PR8) virus infections in mice. Furthermore, the use of PGA/alum allows for chimeric proteins to be spared and vaccine efficacy to be improved, comparable to high doses of chimeric-protein vaccinations in mice. These results suggest that the PGA/ alum-adjuvanted chimeric protein may be a potential UIV candidate against influenza viruses.

\section{Materials and Methods}

Mice

C57BL/6 and BALB/c mice (six to eight weeks old, female) were purchased from Orient Bio Inc. (Republic of Korea). All mice were housed and maintained under specific pathogen-free (SPF) conditions in the Korea Research Institute of Bioscience and Biotechnology (KRIBB). All studies were reviewed and approved by the Institutional Animal Care and Use Committee (IACUC) at the KRIBB (KRIBB-AEC-17161 and KRIBB-AEC16186). All animal experiments were performed according to the Guidelines for Animal Experiments of the KRIBB.

\section{Cells}

Madin-Darby Canine Kidney (MDCK) cells were purchased from the American Type Culture Collection (ATCC) and maintained in Modified Eagle's Medium (MEM; Corning, USA) containing 5\% heat-inactivated fetal bovine serum (FBS; Gibco, USA), $100 \mathrm{U} / \mathrm{ml}$ penicillin, $100 \mathrm{mg} / \mathrm{ml}$ streptomycin (Gibco), and 1\% MEM vitamin solution (Sigma, USA). Splenocytes from immunized mice were cultured in Roswell Park Memorial Institute (RPMI) 1640 medium (Gibco) supplemented with 10\% heat-inactivated FBS, $100 \mathrm{U} / \mathrm{ml}$ penicillin, and $100 \mathrm{mg} / \mathrm{ml}$ streptomycin.

\section{Preparation of PGA/Alum}

$\gamma$-PGA was purchased from BioLeaders (Korea), and PGA/alum was prepared by combining $\gamma$-PGA with Imject alum (Thermo Fisher, USA) in deionized distilled water (DDW) containing $0.9 \%$ saline as previously reported [47]. Briefly, $1 \mathrm{mg} / \mathrm{ml}$ of alum solution (200 ml, $\mathrm{pH} 6.5)$ was added dropwise to $1 \mathrm{mg} / \mathrm{ml}$ of $\gamma$-PGA solution $(200 \mathrm{ml}, \mathrm{pH} 6.8)$ with constant stirring at $600 \mathrm{rpm}$. The combined PGA/alum was centrifuged at $15,000 \times g$ for $30 \mathrm{~min}$ at $4^{\circ} \mathrm{C}$ and resuspended in DDW containing $0.9 \%$ saline. The combined PGA/alum was stored at $4^{\circ} \mathrm{C}$ prior to use.

\section{Construction of Plasmids Expressing 3M2e, 3HA2, NP, and 3M2e-3HA2-NP (Chimeric) Proteins}

The genes of the influenza A/Puerto Rico/8/34 (PR8) strain were used as a template for cloning 3M2e, 3HA2, and NP. The cDNA-encoding three tandem repeats of M2e (amino acid residues 2-24) were cloned by NheI and NotI into pET21a (+) (Novagen, USA). Each M2e sequence was linked by a 6 bp linker (TCTAGC). Three tandem repeats of HA2 (amino acid residues 420-474)-encoding cDNA were cloned by NheI and XhoI into pET21a(+). Each HA2 sequence was linked by a 6 bp linker (TCTAGC). NP (amino acid residues 2-498)-encoding cDNA was also cloned by NheI and XhoI into pET21a(+). To construct the plasmid-containing the 3M2e-3HA2-NP (chimeric) sequence, three tandem repeats of M2e, three tandem repeats of HA2, and NP were linked by G4S linkers to form the chimeric construct. The chimeric construct was cloned by NheI and NotI into pET21a(+). 
Expression and Purification of 3M2e,3HA2, NP, and 3M2e-3HA2-NP (Chimeric) Proteins

The constructs (3M2e, 3HA2, NP, and 3M2e-3HA2-NP) in pET21a $(+)$ containing C-terminal $6 \times$ His-tag were transformed into Escherichia coli $\mathrm{C} 43(\mathrm{DE} 3)$ by heat shock for $30 \mathrm{~s}$ at $42^{\circ} \mathrm{C}$. The transformed cells were selected at $37^{\circ} \mathrm{C}$ on a Luria-Bertani (LB) broth agar plate containing $100 \mu \mathrm{g} / \mathrm{ml}$ of ampicillin (LPS Solution, Korea). A selected single colony was inoculated in $5 \mathrm{ml}$ of LB broth with $100 \mu \mathrm{g} / \mathrm{ml}$ of ampicillin and incubated overnight in a shaking incubator at $200 \mathrm{rpm}$ and $37^{\circ} \mathrm{C}$. The overnight culture was transferred into $500 \mathrm{ml}$ of fresh LB broth with $100 \mu \mathrm{g} / \mathrm{ml}$ of ampicillin and incubated in a shaking incubator at $200 \mathrm{rpm}$ and $37^{\circ} \mathrm{C}$ until the optical density (OD) at $600 \mathrm{~nm}$ reached $0.3-0.6$. Then, isopropyl $\beta$-D-1-thiogalactopyranoside (IPTG) was added to the cells at a final concentration of $1 \mathrm{mM}$ to induce protein expression and then incubated overnight at $160 \mathrm{rpm}$ and $20^{\circ} \mathrm{C}$. After incubation, the cells were centrifuged at $12,000 \times g$ for $30 \mathrm{~min}$ at $4^{\circ} \mathrm{C}$ and stored overnight at $-80^{\circ} \mathrm{C}$. For the purification of proteins, the frozen cells were thawed and resuspended in binding buffer $\left(50 \mathrm{mM} \mathrm{NaH}_{2} \mathrm{PO}_{4}, 0.5 \mathrm{M}\right.$ $\mathrm{NaCl}, 20 \mathrm{mM}$ imidazole, $1 \%$ Triton X-100, $\mathrm{pH}$ 8.0). The resuspended cells were disrupted by sonication on ice, and the soluble fraction was separated by centrifugation at $12,000 \times g$ for $30 \mathrm{~min}$ at $4^{\circ} \mathrm{C}$. The soluble fraction was applied to a Ni-NTA column (Protein Ark, UK) using ÄKTA Explorer (GE Healthcare, USA). After loading the proteins, the column was washed with washing buffer (50 $\mathrm{mM} \mathrm{NaH}_{2} \mathrm{PO}_{4}, 0.5 \mathrm{M} \mathrm{NaCl}, 20 \mathrm{mM}$ imidazole, $\mathrm{pH} 8.0$ ), and proteins were eluted with elution buffer $\left(50 \mathrm{mM} \mathrm{NaH}_{2} \mathrm{PO}_{4}, 0.5 \mathrm{M} \mathrm{NaCl}, 0.5 \mathrm{M}\right.$ imidazole, $\mathrm{pH}$ 8.0). The eluted proteins were concentrated by an Amicon Ultra centrifugal filter (Millipore, USA), followed by size-exclusion chromatography using a HiLoad Superdex 200 column (GE Healthcare) with a size-exclusion buffer (50 mM $\mathrm{NaH}_{2} \mathrm{PO}_{4}, 0.5 \mathrm{M} \mathrm{NaCl}, \mathrm{pH}$ 7.4). The expected proteins were collected, and the buffer was changed with an Amicon Ultra centrifugal filter in phosphate-buffered saline (PBS). Then, purified proteins were concentrated with an Amicon Ultra centrifugal filter, and the protein concentration was determined using a BCA assay kit (Thermo Scientific).

\section{SDS-PAGE and Western Blot}

Purified proteins (chimeric, 3M2e, 3HA2, and NP) were separated by $12-15 \%$ SDS-polyacrylamide gel electrophoresis and visualized by staining with Coomassie blue R-250 (LPS Solution, Korea). For western blot analysis, the proteins separated by $12-15 \%$ SDS-polyacrylamide gel were transferred to polyvinylidene difluoride (PVDF) membranes (Millipore). The membranes were blocked with 5\% skim milk in PBS for $1 \mathrm{~h}$ at room temperature (RT). After blocking, the membranes were washed with PBST (PBS containing $0.1 \%$ Tween-20) and incubated with 1:2000 primary antibodies specific for influenza A H1N1 HA2 (Biorbyt, UK), influenza A M2 (Invitrogen, USA), influenza A NP (Southern Biotech, USA), and Penta·His (Qiagen, The Netherlands) overnight at $4^{\circ} \mathrm{C}$. After washing with PBST, the membranes were incubated with 1:2000 horseradish peroxidase (HRP)conjugated horse anti-mouse IgG or HRP-conjugated goat anti-rabbit IgG (Cell Signaling, USA) for 1h at RT. After being washed with PBST, protein bands were visualized by an enhanced chemiluminescence system (GE Healthcare).

\section{Preparation of Influenza A Viruses}

Influenza A/Puerto Rico/8/34 (PR8; H1N1), A/California/04/09 (CA04; H1N1), and H3N2 carrying HA and NA genes from A/Hong Kong/1/68, as well as six internal genes from A/Puerto Rico/8/34, were provided by Dr. Young Ki Choi (Chungbuk National University, Cheongju, Korea). Influenza A viruses (PR8, CA04, and H3N2) were inoculated into 9-10-day-old SPF-embryonated chicken eggs and incubated for two days at $37^{\circ} \mathrm{C}$. After chilling at $4^{\circ} \mathrm{C}$ overnight, the allantoic fluid containing influenza viruses was collected and centrifuged at $3,500 \times g$ for $10 \mathrm{~min}$ at $4^{\circ} \mathrm{C}$. Then, the allantoic fluid was filtered through a $0.45 \mu \mathrm{m}$ pore-size membrane filter (Millipore) and stored at $-80^{\circ} \mathrm{C}$ until use. All virus experiments were performed under Biosafety Level $2+$ (BSL2+) facilities and conditions.

\section{Immunization and Virus Challenge}

C57BL/6 mice (6-8 weeks old, female) were intramuscularly (i.m.) immunized with 1-15 $\mu$ g of chimeric protein in the presence or absence of $400 \mu \mathrm{g}$ of $\gamma$-PGA, $400 \mu \mathrm{g}$ of alum, and $800 \mu \mathrm{g}$ of PGA/alum on days 0,14 , and 28. Two weeks after the last immunization, the sera from the immunized mice were collected, and the immunized mice were intranasally (i.n.) challenged with a lethal dose (LD) of PR8 $\left(10 \mathrm{LD}_{50}\right), \mathrm{CA} 04\left(20 \mathrm{LD}_{50}\right)$, or H3N2 $(10$ $\mathrm{LD}_{50}$ ). Body weight and survival rate were monitored for 14 days. Mice that had lost more than $25 \%$ of their initial body weight were considered dead and were humanely euthanized.

\section{Enzyme-Linked Immunosorbent Assay (ELISA)}

The level of influenza A virus antigen-specific IgG antibody in the sera from the immunized mice was measured using ELISA. ELISA plates (Nunc, USA) were coated overnight at $4^{\circ} \mathrm{C}$ with $2 \mu \mathrm{g} / \mathrm{ml}$ of $3 \mathrm{M} 2 \mathrm{e}, 3 \mathrm{HA} 2$, and NP in PBS. Antigen-coated plates were washed twice with PBST and blocked with 5\% skim milk in PBS for $1 \mathrm{~h}$ at RT. After washing twice, diluted samples in blocking buffer were added to the plates and 3-fold serially diluted in the plates. After incubation for $2 \mathrm{~h}$, the plates were washed twice, and 1:5000 secondary detection antibodies (horseradish-peroxidase-conjugated goat anti-mouse IgG) were added to the plates. After incubation for $1 \mathrm{~h}$ at RT, plates were washed twice, and $100 \mu \mathrm{l}$ of 3,3,5,5'-tetramethylbenzidine (TMB) was added for the development of the reactions. Reactions were stopped by the addition of $50 \mu \mathrm{l}$ of $1 \mathrm{M}$ sulfuric acid. OD was measured at a wavelength of $450 \mathrm{~nm}$ using a microreader. 


\section{Flow Cytometry}

C57BL/6 mice were i.m. vaccinated with chimeric protein $(1-15 \mu \mathrm{g})$ alone or mixed with $400 \mu \mathrm{g}$ of $\gamma$-PGA, $400 \mu \mathrm{g}$ of alum, and $800 \mu \mathrm{g}$ of PGA/alum on days 0,14 , and 28 . Two weeks after the last vaccination, the mice were sacrificed, and splenocytes were obtained from the mice. Splenocytes $\left(1 \times 10^{6}\right.$ cells/100 $\left.\mu \mathrm{l}\right)$ were blocked with $1 \mu \mathrm{l}$ of anti-CD16/32 monoclonal antibody (mAb; BD Biosciences, USA) and surface-stained with an antibody mixture containing $1 \mu \mathrm{l}$ of anti-CD3e-PerCP (BD Biosciences), anti-CD4-FITC (BD Biosciences), and anti-CD8allophycocyanin (BD Biosciences). After incubation for $30 \mathrm{~min}$ at $4^{\circ} \mathrm{C}$, surface-stained cells were washed twice with PBS. Then, cells were fixed and permeabilized with a BD Cytofix/Cytoperm Kit (BD Biosciences) according to the manufacturer's instructions. Fixed and permeabilized cells were stained with $1 \mu$ of anti-IFN- $\gamma$-PE (BD Biosciences) for $30 \mathrm{~min}$ at $4^{\circ} \mathrm{C}$, and cells were detected by FACSVerse or FACS Calibur flow cytometry (BD Biosciences). FlowJo software (Tree Star, USA) was used for data analysis.

\section{Antibody-Dependent NK Cell Activation}

The $3 \mathrm{HA} 2(2 \mu \mathrm{g} / \mathrm{ml}$, stalk region) protein was coated onto the ELISA plates. Coated plates were washed twice with PBS and incubated with heat-inactivated serum $\left(1 \mathrm{~h}, 56^{\circ} \mathrm{C}\right)$ of the immunized mice for $2 \mathrm{~h}$ at $37^{\circ} \mathrm{C}$. Then, the unbound antibodies in serum were washed twice with PBS. For NK cell preparation, the spleen was isolated from naïve C57BL/6 mice, and splenocytes were obtained from the spleen. NK cells in the splenocytes were purified by an NK cell isolation kit (Miltenyi Biotec, Germany) according to the manufacturer's instructions. Isolated NK cells $\left(1 \times 10^{5}\right.$ cells/well) were added to the wells and incubated with anti-CD107a-PE (BD Biosciences) in the presence of a protein transport inhibitor cocktail (eBioscience, USA) for $6 \mathrm{~h}$ at $37^{\circ} \mathrm{C}$. After incubation, NK cells were harvested, fixed, and permeabilized by a BD Cytofix/Cytoperm Kit (BD Biosciences) according to the manufacturer's instructions. Then, NK cells were stained with anti-IFN- $\gamma$-allophycocyanin (BD Biosciences) and detected by FACSVerse or FACS Calibur flow cytometry (BD Biosciences).

\section{Antibody-Dependent Cellular-Cytotoxicity (ADCC) Assay}

Influenza A viruses (PR8, CA04 or H3N2)-infected MDCK cells (MOI = 1) were harvested and added to Ubottom 96 -well plates at $1 \times 10^{4}$ cells/well. Virus-infected MDCK cells were incubated with heat-inactivated serum $\left(1 \mathrm{~h}, 56^{\circ} \mathrm{C}\right)$ and naïve NK cells $\left(1 \times 10^{4}\right.$ cells/well $)$ for $4 \mathrm{~h}$ at $37^{\circ} \mathrm{C}$. Cytotoxicity of the NK cells was measured by lactate dehydrogenase (LDH) in culture supernatants using a CytoTox 96 non-radioactive cytotoxicity assay (Promega, USA) according to the manufacturer's instructions.

\section{Enzyme-Linked Immunospot (ELISPOT)}

ELISPOT assay was performed with a mouse IFN- $\gamma$ ELISPOT Kit (BD Biosciences) according to the manufacturer's instructions. Briefly, ELISPOT plates were coated with purified anti-IFN- $\gamma$ at $4^{\circ} \mathrm{C}$ overnight. The splenocytes obtained from the immunized mice were plated at $5 \times 10^{5}$ cells/well on the anti-IFN- $\gamma$-coated ELISPOT plates and stimulated with 2000 TCID $_{50}$ of UV-inactivated influenza A viruses (PR8, CA04 or H3N2). After three days, the spot-forming units (SFUs) of IFN- $\gamma$-producing cells were developed by AEC substrate (BD Biosciences).

\section{Hemagglutination-Inhibition (HI) Assay}

$\mathrm{HI}$ titers of the sera against influenza A viruses (PR8, CA04, and H3N2) were determined as described previously [48]. Briefly, the sera from the immunized mice were treated with a receptor-destroying enzyme (RDE; Hardy Diagnostics, USA) and serially 2-fold diluted with PBS in U-bottom 96-well plates. The diluted sera were incubated with $4 \mathrm{HA}$ units $/ 25 \mu \mathrm{l}$ of influenza A viruses (PR8, CA04, or H3N2) for $30 \mathrm{~min}$ at RT. After incubation, $0.7 \%$ turkey red blood cells (RBCs) were added to the sera mixed with the virus and incubated for $30 \mathrm{~min}$ at RT. HI titers were determined by the highest dilution that prevents hemagglutination.

\section{Virus Titers in Lungs}

C57BL/6 mice (6-8 weeks old, female) were i.m. immunized three times with a chimeric protein $(1-15 \mu \mathrm{g})$ in the presence or absence of $400 \mu \mathrm{g}$ of alum, and $800 \mu \mathrm{g}$ of PGA/alum at 2-week intervals. Two weeks after the last vaccination, influenza A viruses (PR8, CA04 or H3N2) were challenged in the mice, and lung samples from the mice were obtained at seven days post-infection (dpi). Lung samples were homogenized in MEM containing $100 \mathrm{U} / \mathrm{ml}$ penicillin, $100 \mathrm{mg} / \mathrm{ml}$ streptomycin, and $1 \%$ MEM vitamin solution and were centrifuged at $12,000 \times g$ for $15 \mathrm{~min}$ at $4^{\circ} \mathrm{C}$. Supernatants were used for virus titration. The virus titers were calculated based on Reed and Muench method [49] and expressed as $\log _{10} 50 \%$ tissue culture infectious dose $\left(\mathrm{TCID}_{50}\right) / \mathrm{ml}$.

\section{Immunohistochemistry}

Immunohistochemistry (IHC) was performed as described previously $[48,50]$. Briefly, the immunized mice (C57BL/6, female) were i.n. challenged with $10 \mathrm{LD}_{50}$ of PR8, $20 \mathrm{LD}_{50}$ of CA04, or $10 \mathrm{LD}_{50}$ of $\mathrm{H} 3 \mathrm{~N} 2$. Seven days after virus infection, the mice were sacrificed and lung tissues from the mice were obtained, fixed with $10 \%$ neutralbuffered formalin, and embedded in paraffin. Formalin-fixed, paraffin-embedded tissue was cut into $4 \mu \mathrm{m}$ sections and mounted onto glass slides. Tissue slides were blocked with $10 \%$ normal goat serum in PBS for $1 \mathrm{~h}$ at RT, washed with PBS containing 0.1\% Triton X-100 (PBSX), and stained with anti-influenza A NP antibody (Southern Biotech, USA) for $2 \mathrm{~h}$ at RT. After washing with PBSX, slides were stained with Alexa Fluor 488conjugated goat anti-mouse IgG (Invitrogen) for $2 \mathrm{~h}$ at RT, followed by staining with $10 \mu \mathrm{g} / \mathrm{ml}$ of $4^{\prime}$,6-diamidino- 
2-phenylindole (DAPI; Sigma, USA) for $10 \mathrm{~min}$ at RT. Then, the stained tissue slides were examined using an LSM5 Pascal confocal fluorescence microscope (Carl Zeiss, Germany).

\section{In Vivo Protection Assay}

To identify whether immune serum from the immunized mice would cross-protect the mice against influenza A viruses (PR8, CA04, or H3N2), in vivo protection assay was carried out as previously described [14, 51]. Briefly, heat-inactivated $\left(56^{\circ} \mathrm{C}, 1 \mathrm{~h}\right)$ immunized serum was mixed with $2 \mathrm{LD}_{50}$ of PR8, $3 \mathrm{LD}_{50}$ of CA04, or $2 \mathrm{LD}_{50}$ of $\mathrm{H} 3 \mathrm{~N} 2$ and incubated for $30 \mathrm{~min}$ at RT. Then, naïve $\mathrm{BALB} / \mathrm{c}$ mice were i.n. infected with the mixture of sera and virus. Body weight and survival rate were monitored for 14 days.

\section{In Vivo Depletion of Immune Cells}

Mice (C57BL/6, female) were immunized three times at 2-week intervals. The mice were infected with $10 \mathrm{LD}_{50}$ of PR8 on day 42 after initial immunization. To deplete immune cells, the mice were intraperitoneally injected with $450 \mu \mathrm{g}$ of anti-CD4 (rat IgG2b; Bio X Cell, USA), anti-CD8 (rat IgG2b; Bio X Cell), anti-NK1.1 (mouse IgG2a; Bio X Cell), or isotype control antibody (mouse IgG2a; Bio X Cell) on days 39, 41, and 43. After virus infections, body weight and survival rate were monitored for 14 days.

\section{Statistical Analysis}

Statistical analysis was performed using GraphPad Prism version 8 (GraphPad Software, USA). Data are presented as the mean \pm standard error of the mean (SEM). Statistically significant difference among multiple groups was assessed using one-way ANOVA/Bonferroni. $P$-values less than 0.05 indicates statistical significance.

\section{Results}

Recombinant 3M2e-3HA2-NP (Chimeric) Protein Expressed and Purified in E. coli

The chimeric protein was composed of $3 \times \mathrm{M} 2 \mathrm{e}, 3 \times \mathrm{HA} 2$, and NP. Amino acid residues 2-24 of M2e, 420-474 of HA2, and 2-498 of NP were expressed simultaneously, and each conserved domain (M2e, HA2, and NP) was connected to a G4S linker in the chimeric protein. The conserved domains of 3M2e, 3HA2, and NP from PR8 virus were synthesized and inserted into a pET21a(+) vector to express the chimeric protein as a vaccine antigen (Figs. 1A-1B). The expressed chimeric protein was detected in SDS-PAGE, and its purity was $>90 \%$ (Fig. 1C). The expression of the purified chimeric protein was confirmed by western blot using anti-His, anti-NP, anti-HA2, and anti-M2e antibodies (Fig. 1D).

Immunization of Chimeric Protein Induces Dose-Dependent Protection Against PR8 Virus

To evaluate the efficacy of the chimeric protein, C57BL/6 mice were i.m. immunized three times with chimeric protein $(0,1,5,10$, and $15 \mu \mathrm{g})$ at 2 -week intervals. Fourteen days after the last immunization, the chimeric proteinimmunized mice were challenged with $10 \mathrm{LD}_{50}$ of the PR8 virus. After PR8 virus infection, body weight decreased for eight days in the chimeric groups $(1,5,10$, and $15 \mu \mathrm{g})$, and the entire PBS group was dead on day 7 . Body weight recovered to the initial body weight dose-dependently in the chimeric groups on day 14, but only the $15 \mu \mathrm{g}$ of chimeric group showed $100 \%$ survival. The other groups had $80 \%$ protection ( 5 and $10 \mu \mathrm{g}$ of chimeric groups) and

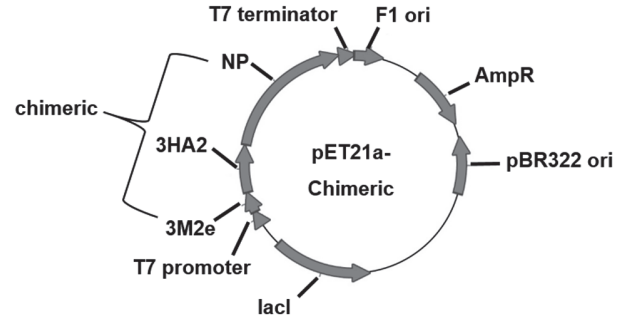

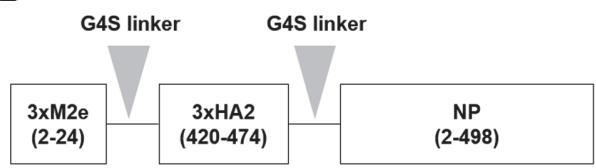

C

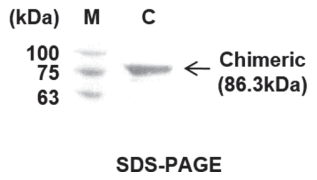

D

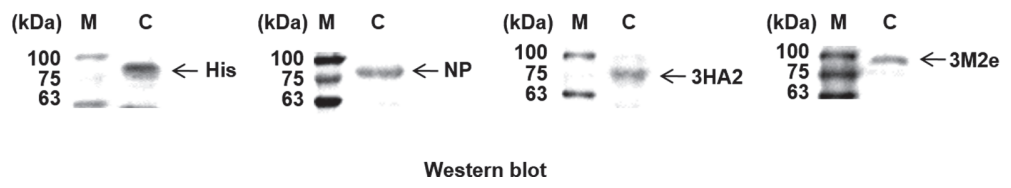

Fig. 1. Vaccine construction and confirmation of purified 3M2e-3HA2-NP (chimeric) protein using the E. coli C43(DE3) expression system. (A) Vector map of the pET21a(+) harboring chimeric protein sequence composed of three tandem repeats of M2e, three tandem repeats of HA2, and NP. (B) Schematic diagram of chimeric protein consisting of components ( $3 \times \mathrm{M} 2 \mathrm{e}, 3 \times \mathrm{HA} 2$, and NP) linked by a G4S linker (gray arrowhead). (C, D) Chimeric protein expressed in E. coli C43(DE3) and purified by His-tag affinity chromatography. Expression was confirmed by (C) SDS-PAGE or (D) western blot (anti-His, anti-NP, anti-HA2, or anti-M2 (containing M2e sequence) antibodies). M, marker; C, chimeric protein. 
A

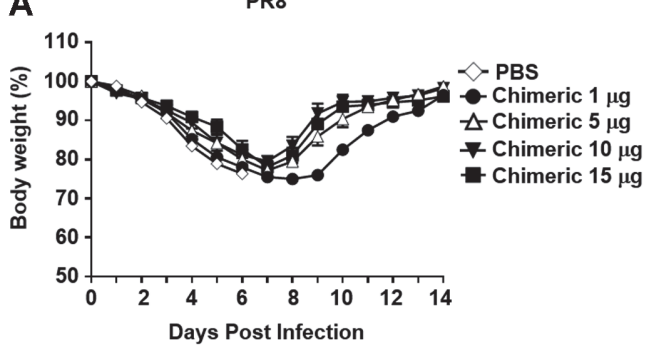

PR8

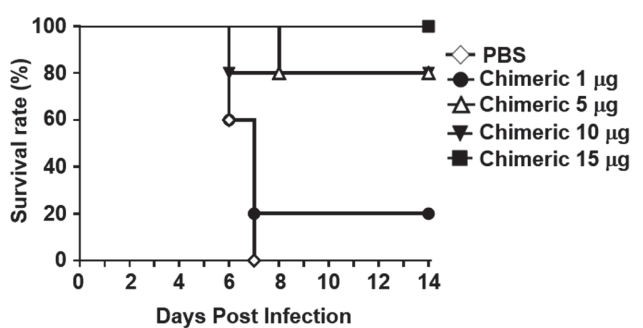

M2e

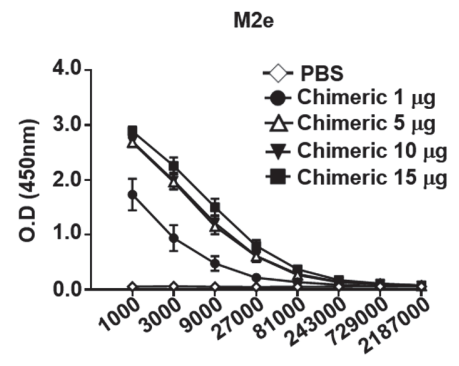

PR8

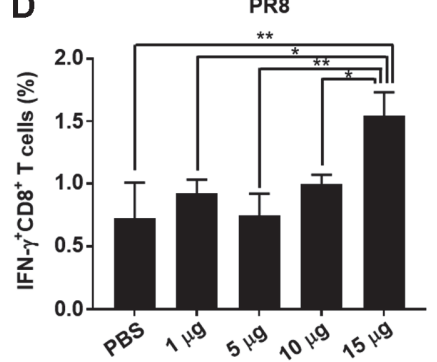

NP

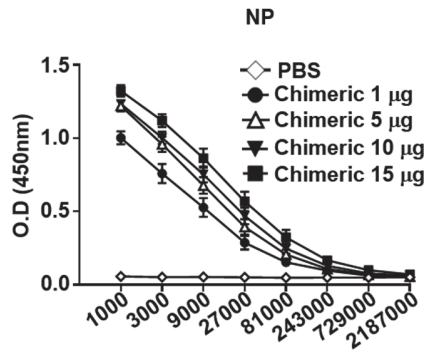

E

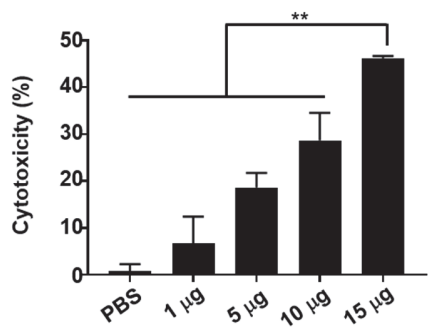

Fig. 2. Vaccination with the chimeric protein induces protection efficacy against the PR8 virus in mice. C57BL/6 mice ( $n=5$ per group) i.m. immunized with $0,1,5,10$, and $15 \mu \mathrm{g}$ of chimeric protein three times at 2 -week intervals. (A) Two weeks after the last vaccination, mice were challenged with $10 \mathrm{LD}_{50}$ of PR8 in vaccinated groups. Body weight and survival rate were measured for two weeks. (B) Sera were collected two weeks after the last immunization. 3HA2-, 3M2e-, or NP-specific IgG in sera determined by ELISA using purified 3HA2, 3M2e, or NP as coating antigens. (C) Viral titers in lung homogenates at 7 dpi were determined by $\mathrm{TCID}_{50}$ assay (N.D, not detected). (D) Splenocytes from immunized mice were stimulated by $2000 \mathrm{TCID}_{50}$ of UV-inactivated PR8 virus. Then, virus-specific IFN- $\gamma^{+} \mathrm{CD}^{+} \mathrm{T}$ cells were detected by flow cytometry. (E) Cytotoxicity of NK cells was measured by lactate dehydrogenase (LDH) assay in PR8-infected MDCK cells $(\mathrm{MOI}=1)$. Data are representative of three independent experiments and expressed as the mean \pm SEM. Statistically significant differences were determined using one-way ANOVA/Bonferroni; ${ }^{*} p<0.05,{ }^{* *} p<0.01$.

20\% protection ( $1 \mu \mathrm{g}$ of chimeric group) against PR8 virus (Fig. $2 \mathrm{~A}$ ).

To evaluate the antibody response of the chimeric protein, conserved domains (3HA2, 3M2e, and NP) were purified and the expression of the proteins was confirmed by SDS-PAGE (Figs. S1A-S1C). The purified proteins were coated onto the plates and diluted sera were incubated for $1 \mathrm{~h}$. IgG antibody titers were measured by ELISA. Results showed that the level of 3HA2-, 3M2e-, or NP-specific IgG was increased dose-dependently, but antibody titers were not significantly different among groups $(0,1,5,10$, and $15 \mu \mathrm{g}$ of chimeric protein; Fig. $2 \mathrm{~B})$. To better understand the efficacy of chimeric protein, viral clearance was examined in lungs from the immunized mice. The mice were i.m. immunized with chimeric protein $(0,1,5,10$, and $15 \mu \mathrm{g})$, and challenged with PR8 virus. Lungs were collected at $7 \mathrm{dpi}$ and viral titers in the lung homogenates were measured by $\mathrm{TCID}_{50}$. The viral titers were significantly reduced dose-dependently and completely cleared in the $15 \mu \mathrm{g}$ of chimeric group at $7 \mathrm{dpi}$ (Fig. 2C).

To detect the involvement of $\mathrm{CD} 8^{+} \mathrm{T}$ cells in chimeric protein vaccination, the frequency of IFN- $\gamma^{+} \mathrm{CD} 8^{+} \mathrm{T}$ cells was detected by flow cytometry to observe CTL response. Analysis of flow cytometry revealed that the $15 \mu \mathrm{g}$ of chimeric group induced significantly higher frequency of IFN $-\gamma^{+} \mathrm{CD} 8^{+} \mathrm{T}$ cells compared with the other groups $(0$, 1,5 , and $10 \mu \mathrm{g}$ of chimeric groups; Fig. 2D). Subsequently, we investigated whether antibodies from the seraprotected mice neutralized the PR8 virus. In vivo protection assay showed that sera from the immunized mice could provide partial protection against the PR8 virus, but did not induce an HI-positive titer against this virus (Figs. S2A and S2B). Non-neutralizing antibody is related to the ADCC response by NK cells [27, 52]. The ADCC response by antibodies and NK cells is an important mechanism for cross-protection against influenza viruses [53, 54]. To detect the cytotoxicity of NK cells against the PR8 virus, PR8-infected MDCK cells were co-cultured with NK cells in the presence of antibodies from the immunized mice. Then, the cytotoxicity of NK cells was measured 
using LDH assay. As shown in Fig. 2E, the cytotoxicity of the chimeric group $(15 \mu \mathrm{g})$ was significantly different from that of the other groups $(0,1,5$, and $10 \mu \mathrm{g}$ of chimeric groups). The $15 \mu \mathrm{g}$ of chimeric group showed the highest cytotoxicity $(46.24 \pm 0.46 \%)$ compared with that of the other groups $(0.74 \pm 1.53 \%$ for PBS, $6.77 \pm 5.68 \%$ for $1 \mu \mathrm{g}$ of chimeric, $18.66 \pm 3.09 \%$ for $5 \mu \mathrm{g}$ of chimeric, and $28.67 \pm 5.91 \%$ for $10 \mu \mathrm{g}$ of chimeric) in PR8-infected MDCK cells. These data indicate that the chimeric protein induces antibody responses, ADCC by NK cells, and $\mathrm{CD} 8^{+} \mathrm{T}$ cell activation against the $\mathrm{PR} 8$ virus.

PGA/Alum Enhances Cross-Reactivity of Chimeric Protein Against Influenza A Viruses

To spare the dose and enhance the vaccine efficacy of chimeric protein, PGA/alum was used as an adjuvant. Mice were vaccinated with $1 \mu \mathrm{g}$ of chimeric protein with PGA/alum. Fig. 3A shows that PGA/alum enhanced the efficacy of the chimeric protein compared with the chimeric protein alone after homologous PR8 virus infection. Mice immunized with PGA/alum-adjuvanted chimeric protein showed less severe reduction of body weight than other groups (PBS, chimeric, and chimeric with alum groups). PGA/alum-adjuvanted chimeric conferred $100 \%$ protection, but chimeric alone and chimeric with alum provided only $20 \%$ and $40 \%$ protection, respectively, to the mice. The PBS group had $0 \%$ protection. Moreover, the effect of $\gamma$-PGA as an adjuvant was investigated with chimeric protein to compare it with PGA/alum. As shown in Figs. S3A-S3C, $\gamma$-PGA provided weak adjuvant effects on chimeric protein compared to PGA/alum against PR8 virus.

Intrasubtypic protection was also investigated in $1 \mu \mathrm{g}$ of chimeric with PGA/alum-vaccinated mice after intrasubtypic CA04 (H1N1) virus challenge. The PGA/alum-adjuvanted chimeric group showed 100\% protection in mice, but chimeric alone and chimeric with alum conferred $20 \%$ and $60 \%$ survival, respectively. The entire PBS group was dead after virus infection (Fig. 3B). Heterosubtypic cross-protection of $5 \mu \mathrm{g}$ of chimeric with PGA/alum was also examined after H3N2 virus infection. The results indicated that PGA/alum-adjuvanted chimeric provided $80 \%$ protection to the mice, and chimeric alone and chimeric with alum protected $20 \%$ of the vaccinated mice after virus infection. The PBS group did not gain any protection (Fig. 3C). These results suggest that PGA/alum improves the efficacy of the chimeric protein and enhances its cross-protection against homo- and heterosubtypic influenza viruses.

To better ascertain the efficacy of PGA/alum-adjuvanted chimeric protein, viral clearance was investigated in mice. The mice were i.m. immunized with chimeric protein $(1 \mathrm{or} 5 \mu \mathrm{g})$ in the presence or absence of alum or PGA/ alum three times, and the vaccinated mice were challenged with influenza A viruses (PR8, CA04, and H3N2). Then, lungs were isolated from the mice at $7 \mathrm{dpi}$, and viral titers were measured in lung homogenates. As shown in Fig. 3D, the viral titer level was significantly reduced in PGA/alum-adjuvanted chimeric compared with that in PBS, chimeric, and chimeric with alum groups at $7 \mathrm{dpi}$. To confirm the reduction of viral titer in the lungs, the NP protein of influenza A viruses was detected by immunofluorescence confocal microscopy. As expected, the NP protein was rarely observed in the chimeric with PGA/alum, but other groups (PBS, chimeric, and chimeric with alum groups) clearly exhibited the presence of influenza A viruses under confocal microscopy (Fig. 3E). These results reveal that PGA/alum increases the efficacy of the chimeric protein to clear viruses in the lungs after influenza A virus infection.

PGA/Alum Increases Virus-Specific Humoral and Cellular Immune Responses of Chimeric Protein

The humoral and cellular immune responses of the PGA/alum-adjuvanted chimeric protein were investigated to better understand the effect of PGA/alum on the chimeric protein. To evaluate the antibody responses of the PGA/alum-adjuvanted chimeric protein, IgG antibody titers against 3HA, 3M2e, and NP of the chimeric protein were measured by ELISA. As shown in Fig. 4A, 3HA2, 3M2e, and NP-specific IgG titers were highest in the PGA/ alum-adjuvanted chimeric group compared with those in the other groups (PBS, chimeric, and chimeric with alum groups). However, the antibodies provided partial protection against influenza A viruses and could not induce an HI-positive titer against the viruses (PR8, CA04, and H3N2) in the PGA/alum-adjuvanted chimeric group (Figs. S4A and S4B).

To further understand the mechanism of PGA/alum-adjuvanted chimeric protein, we examined the binding affinity of IgG antibodies against influenza A viruses, NK cell activation, and ADCC activity by NK cells. As shown in Fig. S5A, the binding affinity of IgG antibodies was highest in the PGA/alum-adjuvanted chimeric group and was significantly different from the other groups (PBS, chimeric, and chimeric with alum). Moreover, the frequency of the activated NK cells $\left(\mathrm{CD} 107 \mathrm{a}^{+}\right.$IFN- $\gamma^{+} \mathrm{NK}$ cells) was also highest in PGA/alum-adjuvanted chimeric group compared with that in the other groups (PBS, chimeric, and chimeric with alum groups) by flow cytometry analysis (Fig. S5B).

To ascertain the cross-reactivity of T cells, mice were vaccinated with chimeric, chimeric with alum, and PGA/ alum-adjuvanted chimeric. Then, splenocytes from the immunized mice were harvested and activated with three different UV-inactivated influenza A viruses (PR8, CA04, or H3N2). As shown in Fig. 4B, ELISPOT analysis revealed that the PGA/alum-adjuvanted chimeric produced more PR8-, CA04-, and H3N2-specific IFN- $\gamma$ secreting cells compared with the other groups (PBS, chimeric, and chimeric with alum groups). To further identify cross-reactive $\mathrm{CD} 8^{+} \mathrm{T}$ cells, IFN- $\gamma$ secreting $\mathrm{CD} 8^{+} \mathrm{T}$ cells were detected by flow cytometry after treatment of UV-inactivated influenza A viruses (PR8, CA04, or H3N2). Results showed that the frequency of IFN- $\gamma^{+} \mathrm{CD} 8^{+}$ T cells was significantly increased by the PGA/alum-adjuvanted chimeric compared with that in the other groups (Figs. S6A- S6C).

For the ADCC assay, the cytotoxicity of the NK cells was examined using an LDH assay. In PR8-infected MDCK cells, the PGA/alum-adjuvanted chimeric group had the highest cytolysis activity $(34.74 \pm 2.11 \%)$ compared with that of other groups $(2.47 \pm 0.87 \%$ for PBS, $3.92 \pm 2.64 \%$ for chimeric, and $10.73 \pm 3.50 \%$ for chimeric with alum 

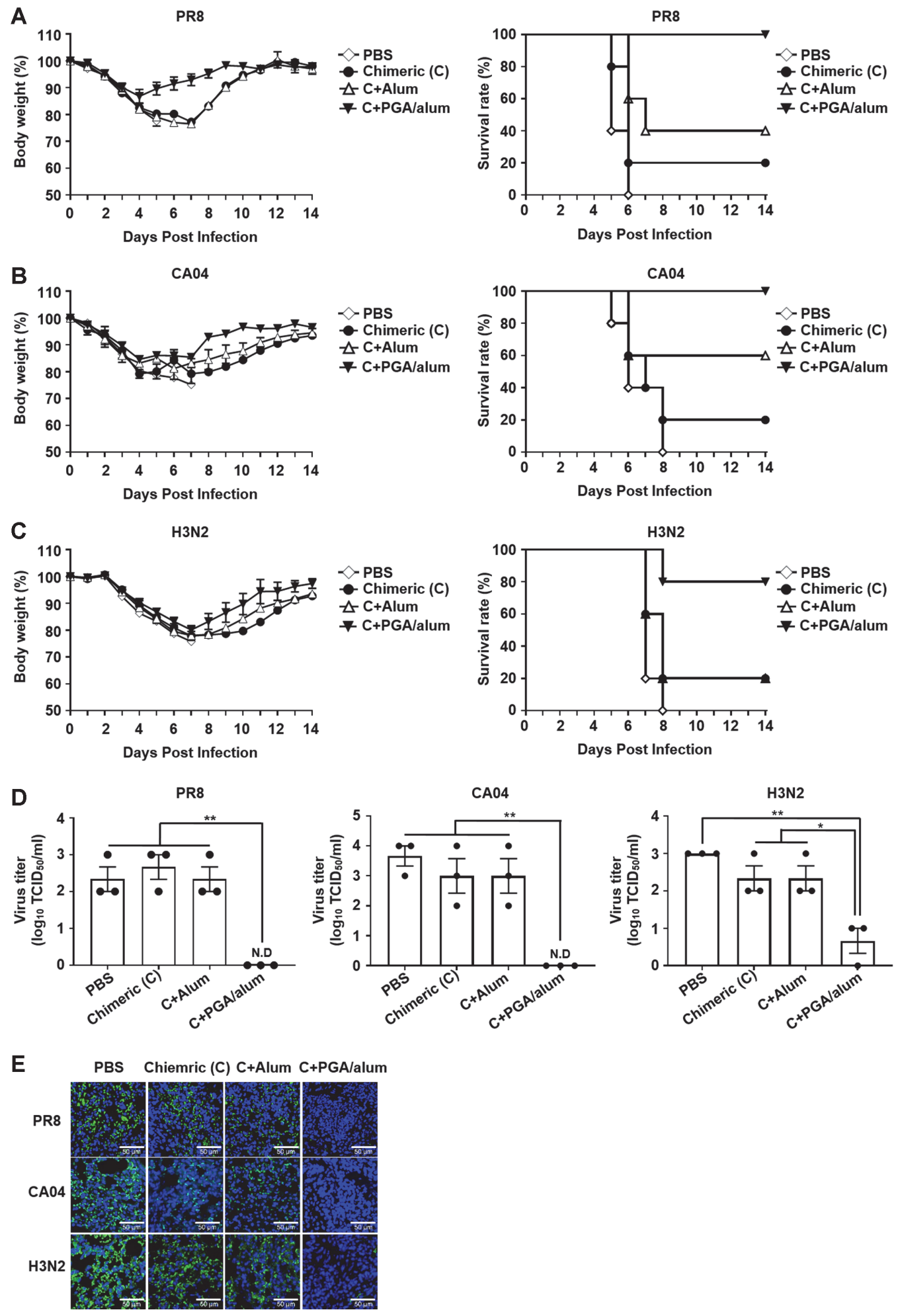

Fig. 3. Cross-reactivity of the chimeric protein against influenza A viruses is enhanced by PGA/alum. C57BL/6 mice ( $n=5$ per group) were i.m. vaccinated with $(\mathbf{A}, \mathbf{B}) 1$ or $(\mathbf{C}) 5 \mu \mathrm{g}$ of chimeric protein with alum or PGA/alum three times at 2-week intervals. Two weeks after the last vaccination, the mice were challenged with (A) $10 \mathrm{LD}_{50}$ of PR8, (B) $20 \mathrm{LD}_{50}$ of CA04, or (C) $10 \mathrm{LD}_{50}$ of H3N2. (A-C) Body weight and survival rate were measured for two weeks. (D) Lungs were aseptically collected from vaccinated mice at $7 \mathrm{dpi}$, and the viral titer in lung homogenates was determined by $\mathrm{TCID}_{50}$ assay (N.D, not detected). (E) Influenza viruses in lung tissues from immunized mice were detected by confocal microscopy using anti-NP antibody and Alexa Fluor 488-conjugated goat anti-mouse IgG after influenza A virus (PR8, CA04, or H3N2) challenge. Scale bar, $50 \mu \mathrm{m}$. Data are expressed as the mean \pm SEM. Statistical significance was determined by one-way ANOVA/Bonferroni; ${ }^{*} p<0.05,{ }^{* *} p<0.01$. 
A
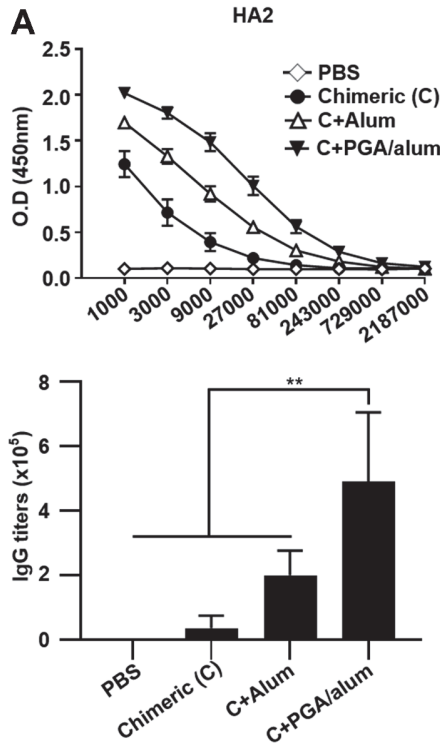

B

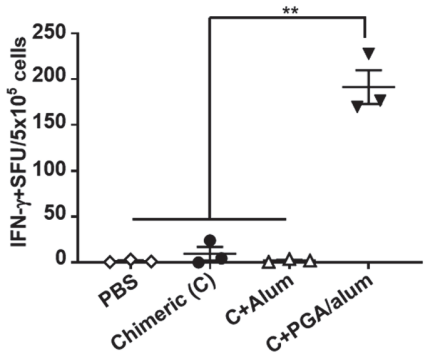

C

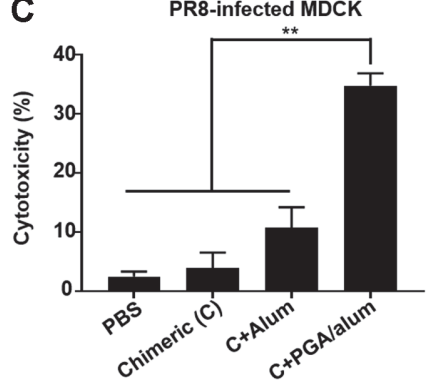

M2e
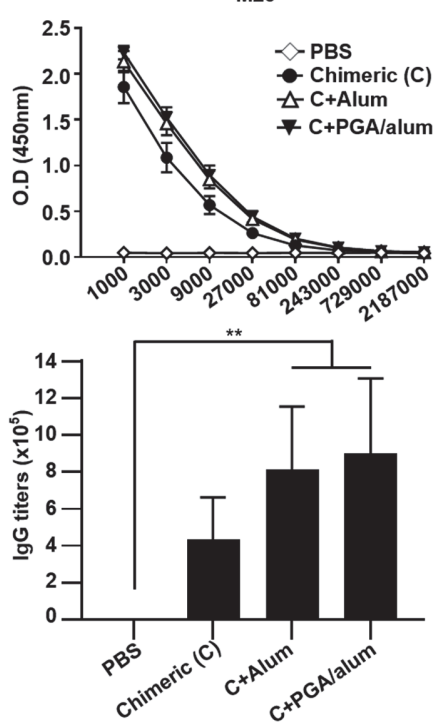

CA04

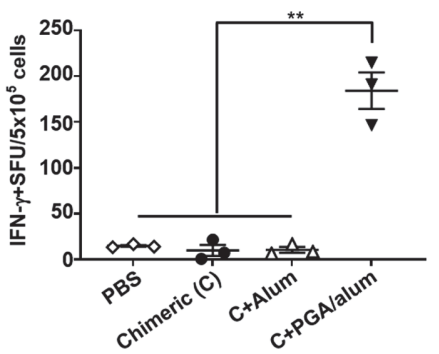

CA04-infected MDCK

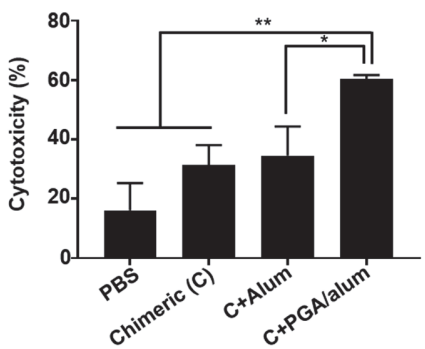

NP
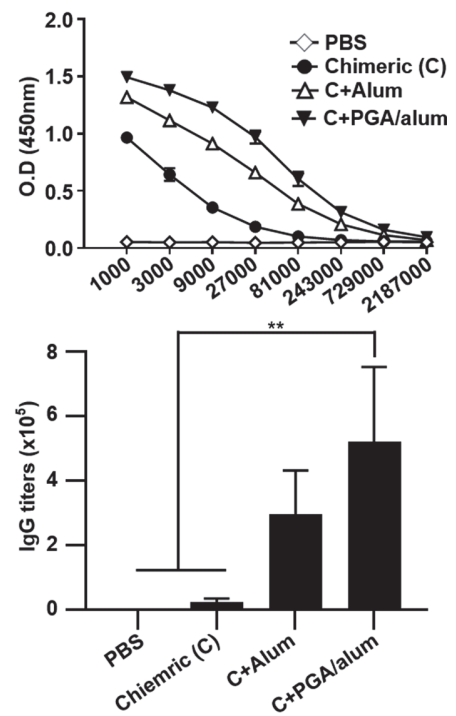

H3N2

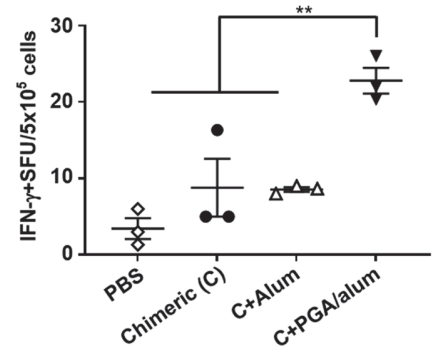

H3N2-infected MDCK

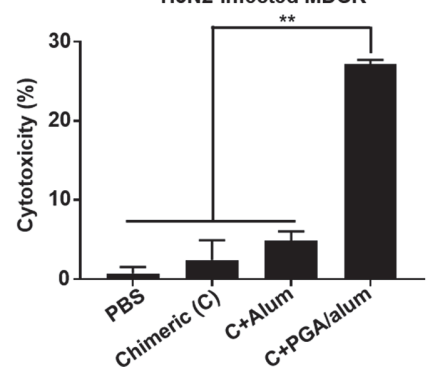

Fig. 4. PGA/alum enhances humoral and cellular immune responses of the chimeric protein against influenza A viruses. C57BL/6 ( $n=5$ per group) vaccinated i.m. three times with 1 or $5 \mu$ g of chimeric protein in the presence or absence of alum and PGA/alum. (A) Two weeks after the last vaccination, sera were collected from immunized mice. Conserved domains (3HA2, 3M2e, and NP) of the chimeric protein were coated in plates and diluted-sera of immunized mice were incubated for $1 \mathrm{~h}$. IgG antibody titers were measured by ELISA assay. (B) Splenocytes from immunized mice were stimulated by 2000 TCID $_{50}$ of UV-inactivated viruses (PR8, CA04, and H3N2). Then, virus-specific T cells were detected by ELISPOT. (C) NK cell cytotoxicity against influenza A viruses (PR8, CA04, and H3N2) was measured by LDH assay. Data are shown as the mean \pm SEM. Statistically significant differences were determined by one-way ANOVA/Bonferroni; ${ }^{\star} p<0.05,{ }^{\star *} p<0.01$.

groups). Similarly, the cytotoxicity of the PGA/alum-adjuvanted chimeric group was significantly higher $(60.33 \pm$ $1.40 \%)$ than that of PBS $(16.13 \pm 9.18 \%)$, chimeric $(31.29 \pm 6.78 \%)$, and chimeric with alum $(34.56 \pm 9.80 \%)$ groups in intrasubtypic CA04-infected MDCK cells. Moreover, the PGA/alum-adjuvanted chimeric group had significantly higher cytotoxicity $(27.16 \pm 0.56 \%)$ than that of PBS $(0.72 \pm 0.82 \%)$, chimeric $(2.41 \pm 2.51 \%)$ and chimeric with alum $(4.86 \pm 1.17 \%)$ groups in heterosubtypic H3N2-infected MDCK cells (Fig. 4C).

Taken together, these findings demonstrate that PGA/alum enhances the cross-protection of the chimeric protein against influenza A viruses through humoral and cellular immunities. 


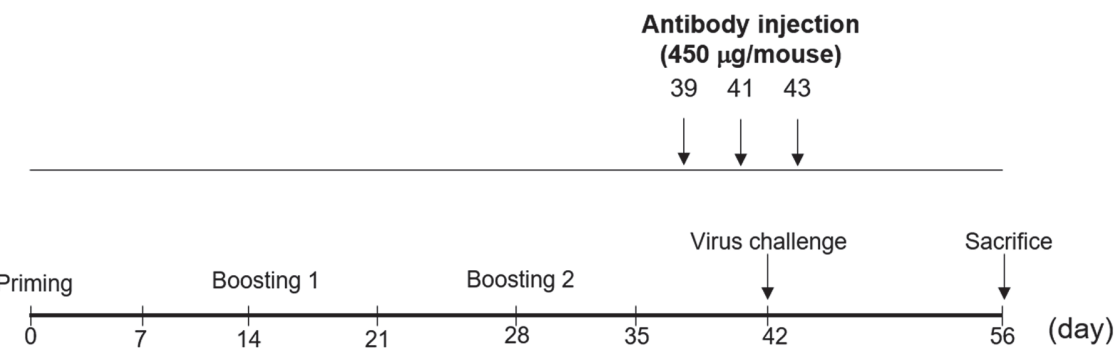

B

PR8

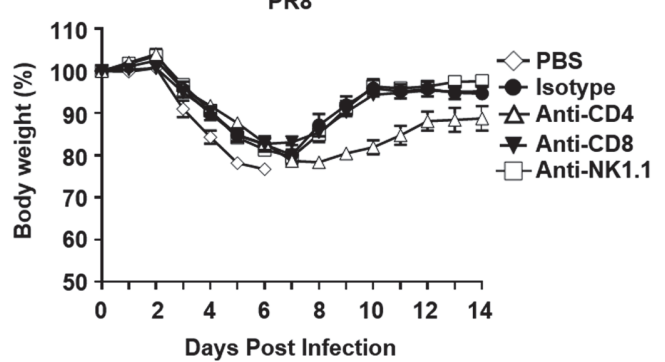

PR8

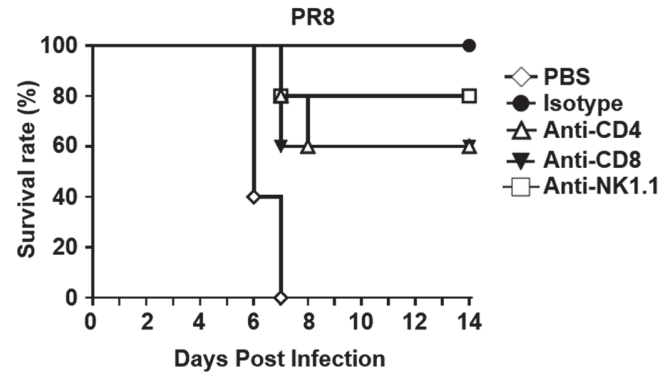

Fig. 5. Protection of the PGA/alum-adjuvanted chimeric protein against the PR8 virus was impaired in the absence of NK and T cells. (A) Experimental schedule of vaccination and antibody depletion. (B) C57BL/6 mice $(n=5$ per group) were i.m. immunized three times with $1 \mu \mathrm{g}$ of chimeric protein in the presence of $800 \mu \mathrm{g}$ of PGA/alum on days 0,14 , and 28. On day 42 , mice were challenged with $10 \mathrm{LD}_{50}$ of the PR8 virus. For depletion of $\mathrm{CD}^{+} \mathrm{T}, \mathrm{CD} 8^{+} \mathrm{T}$, or NK cells, $450 \mu \mathrm{g}$ of antibodies (anti-CD4, anti-CD8, or anti-NK1.1) was injected on days 39, 41, and 43. Body weight and survival rate were monitored for two weeks after the virus challenge.

\section{Depletion of NK and T Cells Blocks Protection of PGA/Alum-Adjuvanted Chimeric Protein Against PR8 Virus}

To confirm whether the protection efficacy of mice vaccinated with PGA/alum-adjuvanted chimeric was mediated by $\mathrm{CD}^{+} \mathrm{T}, \mathrm{CD} 8^{+} \mathrm{T}$, and NK cells, C57BL/ 6 mice were i.m. immunized three times in the presence of $800 \mu \mathrm{g}$ of PGA/alum. Two weeks after the last vaccination, the mice were challenged with $10 \mathrm{LD}_{50}$ of the PR8 virus. For the depletion of $\mathrm{CD} 4^{+} \mathrm{T}, \mathrm{CD} 8^{+} \mathrm{T}$, or NK cells, $450 \mu \mathrm{g}$ of the antibody was injected intraperitoneally in the mice (Fig. 5A). As shown in Fig. 5B, the depletion of CD4, anti-CD8, or anti-NK1.1 reduced the percentage of survival compared with the isotype control $\left(100 \%\right.$ survival rate) in the vaccinated mice after the PR8 challenge. The CD4 ${ }^{+}$ $\mathrm{T}$ or $\mathrm{CD} 8^{+} \mathrm{T}$ cell-depleted group had $60 \%$ protection, and NK cell-depleted mice were $80 \%$ protected after the PR 8 challenge. The entire PBS group was dead ( $0 \%$ survival rate). Taken together, our results demonstrate that $\mathrm{CD} 4^{+} \mathrm{T}$, $\mathrm{CD}^{+} \mathrm{T}$, and NK cells play major roles in protection against influenza virus in mice vaccinated with the PGA/ alum-adjuvanted chimeric protein.

\section{Discussion}

To produce an influenza virus vaccine, circulating virus strains are predicted, and virus vaccines are reformulated every year to induce immune responses toward those virus strains. However, antigenic mismatch between the circulating virus strains and vaccine antigens is a limitation of current influenza virus vaccines. In this study, the 3M2e-3HA-NP (chimeric) protein was constructed with conserved domains derived from the PR8 virus and vaccinated into mice. A PGA/alum adjuvant was also used to spare the dose and improve the efficacy of the chimeric protein. Our findings indicate that the PGA/alum-adjuvanted chimeric protein confers both homologous and heterologous protection against influenza A viruses by inducing virus-specific humoral and cellular immunity.

Accumulating reports indicate that HA2 might be a major target for broad protection against influenza A viruses because HA 2 can induce broadly active anti-hemagglutinin antibodies against influenza A viruses $[16,55$, 56]. Moreover, M2e has been widely used as a candidate of recombinant vaccines for cross-protection against influenza A viruses [29]. M2e is limited in inducing a strong immune response because it is too small to have high immunogenicity. M2e only promotes weak and transient immune responses against influenza viruses [57-59]. However, virus-like particles containing M2e can induce cross-protection, and a mucosal adjuvant enhances the immunogenicity of M2e against influenza A viruses [51,60]. In addition, recombinant proteins NP-M2e or HA2M2e elicit heterologous protection against influenza viruses by promoting robust immune responses [17, 38]. Because a current trend in the design of a universal influenza vaccine is the construction of recombinant proteins targeting various conserved epitopes of viral proteins (M2e, HA2, NP), we constructed and used chimeric protein (3M2e-3HA2-NP) as a universal vaccine antigen. Recently, various studies have been undertaken to check the cross-reactive vaccine effect of influenza chimeric proteins (HA2 and M2e) [44-46]. However, the cross-reactivity 
of adjuvanted chimeric protein 3M2e-3HA2-NP has never been investigated. In this study, we focused on the adjuvant effect of $3 \mathrm{M} 2 \mathrm{e}-3 \mathrm{HA} 2-\mathrm{NP}$ to enhance the antigen dose-sparing effects as well as cross-protection of chimeric protein vaccine antigen.

The chimeric protein $(15 \mu \mathrm{g})$ could induce $100 \%$ protection against the PR8 virus, and the virus in the lungs was cleared at $7 \mathrm{dpi}$, which means that the chimeric protein induced sufficient protection against the PR8 virus. In the antibody responses, the antibody level was dose-dependently increased against 3HA2, 3M2e, and NP proteins. The antibodies produced in response to $15 \mu \mathrm{g}$ of chimeric protein could provide superior protection (60\%) for mice compared with that of other groups ( $0 \mu \mathrm{g}$ for $0 \% ; 1,5$, and $10 \mu \mathrm{g}$ for $20 \%)$ (Fig. S2A) even though the level of IgG in response to $15 \mu \mathrm{g}$ of the chimeric protein was not significantly different from that of other groups $(0,1,5$, and $10 \mu \mathrm{g}$ of chimeric protein). Thus, the antibody response induced by the chimeric protein could be involved in protection, and relevantly, the recombinant protein could promote an antibody response and protect mice against influenza viruses $[61,62]$. In addition to the antibody response, $15 \mu \mathrm{g}$ of the chimeric protein induced significantly higher IFN- $\gamma^{+} \mathrm{CD}^{+} \mathrm{T}$ cells compared with the low doses $(0,1,5$, and $10 \mu \mathrm{g})$ of the chimeric protein groups. The induction of IFN- $\gamma^{+} \mathrm{CD}^{+} \mathrm{T}$ cells by the chimeric protein is associated with the nucleoprotein of influenza virus that contains $\mathrm{CD} 8^{+} \mathrm{T}$ cell epitopes $[40,41]$. Therefore, we propose that $15 \mu \mathrm{g}$ of the chimeric protein induces sufficient immune responses and protection against the PR8 virus, which is mediated by both humoral and cellular immunity.

Recently, ADCC was reported to provide proper protection against various viruses, such as the influenza, human-immunodeficiency, and Epstein-Barr viruses [27, 63, 64]. Previous reports demonstrated that HA2 could induce ADCC-mediating antibodies $[53,65]$. Consistent with these reports, the cytotoxicity of NK cells induced by the chimeric protein was dose-dependently increased and was significantly higher in the $15 \mu \mathrm{g}$ of chimeric protein group than in the other groups $(0,1,5$, and $10 \mu \mathrm{g}$ of chimeric groups). Thus, our findings suggest that the chimeric protein induced antibodies that could activate ADCC by NK cells. We also measured the level of IgG antibodies against $3 \mathrm{HA} 2,3 \mathrm{M} 2 \mathrm{e}$, and $\mathrm{NP}$ of the influenza $\mathrm{A}$ virus after vaccination with the chimeric protein in the presence or absence of adjuvants. The level of antibodies against 3HA2, 3M2e, and NP was enhanced by PGA/ alum compared with chimeric alone or chimeric with alum. As expected, the antibodies were not positive in the $\mathrm{HI}$ assay because of the lack of the HA1 domain in the chimeric protein (Figs. S2B and S4B). Thus, we investigated the ADCC response by NK cells to identify whether the HA2-mediated antibody could be involved in ADCC. Surprisingly, the PGA/alum-adjuvanted chimeric protein substantially induced cytotoxicity against the virusinfected target cells and it was significantly higher than that of other groups in the ADCC assay. Taken together, we propose that the PGA/alum-adjuvanted chimeric protein promotes ADCC response against viral infection.

A crucial drawback of current influenza vaccines is that they will not prevent another pandemic in the future because they are strain-specific, not inducing cross-protection against other influenza viruses. It was reported that $\mathrm{CD}^{+} \mathrm{T}$ cells are critical factors for cross-protection [14,39]. In this study, we investigated whether IFN- $\gamma^{+} \mathrm{CD} 8^{+} \mathrm{T}$ cells were significantly increased after vaccination with the PGA/alum-adjuvanted chimeric protein. Interestingly, PGA/alum significantly enhanced the induction of IFN $-\gamma^{+} \mathrm{CD}^{+} \mathrm{T}$ cells by low doses $(1 \mathrm{or} 5 \mu \mathrm{g})$ of the chimeric protein compared with chimeric alone or alum-adjuvanted chimeric protein. Our findings suggest that PGA/alum increases induction of IFN- $\gamma^{+} \mathrm{CD} 8^{+} \mathrm{T}$ cells in response to the chimeric protein, which is involved in cross-protection. Furthermore, our results showed that $1 \mu \mathrm{g}$ of the chimeric protein with PGA/alum could confer similar protection against the PR8 virus compared with $15 \mu \mathrm{g}$ of the chimeric protein. Thus, we propose that PGA/alum could be a suitable influenza vaccine adjuvant for cross-protection.

$\mathrm{CD} 4^{+} \mathrm{T}$ cells induce antibody production by $\mathrm{B}$ cells to promote viral clearance in influenza virus infection [66$68]$ and $\mathrm{CD}^{+} \mathrm{T}$ cells play a critical role in cross-protection against multiple influenza viruses [14, 39]. NK cellmediated ADCC is also important for cross-protection against influenza A viruses [27]. Thus, depletion of these immune cells $\left(\mathrm{CD}^{+} \mathrm{T}, \mathrm{CD} 8^{+} \mathrm{T}\right.$, or NK cells) may impair cross-protection against influenza viruses. In the present study, we depleted immune cells to confirm the effects of $\mathrm{CD} 4^{+} \mathrm{T}, \mathrm{CD} 8^{+} \mathrm{T}$, or NK cells in PGA/alum-adjuvanted chimeric group. As expected, the survival rate was decreased after treatment of anti-CD4, anti-CD8, or antiNK1.1 antibodies in PGA/alum-adjuvanted chimeric group (Fig. 5B), which means CD4 ${ }^{+}$T, CD8 ${ }^{+} \mathrm{T}$, or NK cells are involved in the protective effects of PGA/alum-adjuvanted chimeric protein.

Alum or $\gamma$-PGA-adjuvanted chimeric protein provided partial protection to mice (Figs. 3A-3C and Figs S3A$\mathrm{S} 3 \mathrm{C}$ ). However, PGA/alum-adjuvanted chimeric protein conferred higher protection using the same chimeric dose compared with other adjuvants (alum or $\gamma$-PGA). Previously, we used an influenza split vaccine antigen kindly provided by Green Cross Corp. to investigate the adjuvant effect of PGA/alum. In this study, we used a chimeric recombinant protein (3M2e-3HA2-NP) as a vaccine antigen adjuvanted with PGA/alum to investigate heterosubtypic cross-reactivity. Mice vaccinated with chimeric protein only $(15 \mu \mathrm{g})$ induced $100 \%$ protection against homologous virus (PR8; H1N1). Following heterologous virus challenge, the mice vaccinated with PGA/ alum adjuvanted chimeric protein $(1 \mu \mathrm{g})$ showed similar protection compared with those immunized with PGA/ alum adjuvanted split vaccine. The pandemic vaccine is the most effective way to control the infection of pandemic influenza virus. However, it usually takes more than six months to develop influenza vaccine. If a highly effective heterosubtypic cross-reactive influenza vaccine is available, we could develop it for emergency use during an influenza pandemic. Thus, PGA/alum-adjuvanted chimeric vaccine may be a candidate universal vaccine for emergency use during influenza pandemics.

In summary, the chimeric protein is an influenza vaccine antigen that induces humoral and cellular immunity such as CTL and ADCC response. The cross-reactive effects of the chimeric protein were enhanced by PGA/alum. Thus, chimeric protein with PGA/alum cross-protected mice against heterologous influenza A viruses. Therefore, the PGA/alum-adjuvanted chimeric protein may be a promising universal influenza vaccine candidate. 


\section{Acknowledgments}

This research was funded by grants from the Korea Research Institute of Bioscience and Biotechnology (KRIBB) Research Initiative Program (KGM9942011) and from the National Research Foundation of Korea (NRF) through the Korea government (NRF-2018M3A9H4055203). We would like to thank Dr. Young Ki Choi and Young-Il Kim in the Department of Microbiology, College of Medicine and Medical Research Institute, Chungbuk National University for their technical support.

\section{Conflicts of Interest}

The authors have no financial conflicts of interest to declare.

\section{References}

1. Palese P. 2004. Influenza: old and new threats. Nat. Med. 10: S82-87.

2. Te Velthuis AJ, Fodor E. 2016. Influenza virus RNA polymerase: insights into the mechanisms of viral RNA synthesis. Nat. Rev. Microbiol. 14: 479-493.

3. Chen J, Deng YM. 2009. Influenza virus antigenic variation, host antibody production and new approach to control epidemics. Virol. J. 6: 30 .

4. World Health Organization. 2018. Influenza (Seasonal). Available from https://www.who.int/news-room/fact-sheets/detail/ influenza-(seasonal). Accessed Nov. 10, 2020.

5. Webster RG, Laver WG. 1972. The origin of pandemic influenza. Bull World Health Organ. 47: 449-452.

6. Nichol KL, Treanor JJ. 2006. Vaccines for seasonal and pandemic influenza. J. Infect. Dis. 194 Suppl 2: S111-118.

7. Gerhard W, Mozdzanowska K, Zharikova D. 2006. Prospects for universal influenza virus vaccine. Emerg. Infect. Dis. 12: 569-574.

8. Atmar RL, Keitel WA, Cate TR, Munoz FM, Ruben F, Couch RB. 2007. A dose-response evaluation of inactivated influenza vaccine given intranasally and intramuscularly to healthy young adults. Vaccine 25: 5367-5373.

9. Martin Mdel P, Seth S, Koutsonanos DG, Jacob J, Compans RW, Skountzou I. 2010. Adjuvanted influenza vaccine administered intradermally elicits robust long-term immune responses that confer protection from lethal challenge. PLoS One 5: e10897.

10. Ada GL, Jones PD. 1986. The immune response to influenza infection. Curr. Top Microbiol. Immunol. 128: 1-54.

11. Smith DJ, Lapedes AS, de Jong JC, Bestebroer TM, Rimmelzwaan GF, Osterhaus AD, et al. 2004. Mapping the antigenic and genetic evolution of influenza virus. Science 305: 371-376.

12. van de Sandt CE, Kreijtz JH, Rimmelzwaan GF. 2012. Evasion of influenza A viruses from innate and adaptive immune responses. Viruses 4: 1438-1476.

13. Saunders-Hastings PR, Krewski D. 2016. Reviewing the history of pandemic influenza: Understanding patterns of emergence and transmission. Pathogens. 5: 66.

14. Lee YN, Lee YT, Kim MC, Gewirtz AT, Kang SM. 2016. A novel vaccination strategy mediating the induction of lung-resident memory CD8 T cells confers heterosubtypic immunity against future pandemic influenza virus. J. Immunol. 196: 2637-2645.

15. Wang W, Huang B, Jiang T, Wang X, Qi X, Tan W, et al. 2014. Maximal immune response and cross protection by influenza virus nucleoprotein derived from $E$. coli using an optimized formulation. Virology 468-470: 265-273.

16. Steel J, Lowen AC, Wang TT, Yondola M, Gao Q, Haye K, et al. 2010. Influenza virus vaccine based on the conserved hemagglutinin stalk domain. mBio 1: e00018-10.

17. Wang W, Huang B, Jiang T, Wang X, Qi X, Gao Y, et al. 2012. Robust immunity and heterologous protection against influenza in mice elicited by a novel recombinant NP-M2e fusion protein expressed in E. coli. PLoS One 7: e52488.

18. Lee YN, Kim MC, Lee YT, Hwang HS, Lee J, Kim C, et al. 2015. Cross protection against influenza A virus by yeast-expressed heterologous tandem repeat M2 extracellular proteins. PLoS One 10: $\mathrm{e} 0137822$.

19. Goff PH, Eggink D, Seibert CW, Hai R, Martinez-Gil L, Krammer F, et al. 2013. Adjuvants and immunization strategies to induce influenza virus hemagglutinin stalk antibodies. PLoS One 8: e79194.

20. Shim BS, Choi YK, Yun CH, Lee EG, Jeon YS, Park SM, et al. 2011. Sublingual immunization with M2-based vaccine induces broad protective immunity against influenza. PLoS One 6: e27953.

21. Skehel JJ, Wiley DC. 2000. Receptor binding and membrane fusion in virus entry: the influenza hemagglutinin. Annu. Rev. Biochem. 69: 531-569.

22. Cross KJ, Langley WA, Russell RJ, Skehel JJ, Steinhauer DA. 2009. Composition and functions of the influenza fusion peptide. Protein Pept. Lett. 16: 766-778.

23. Mallajosyula VV, Citron M, Ferrara F, Lu X, Callahan C, Heidecker GJ, et al. 2014. Influenza hemagglutinin stem-fragment immunogen elicits broadly neutralizing antibodies and confers heterologous protection. Proc. Natl. Acad. Sci. USA 111: E2514-2523.

24. Tan GS, Krammer F, Eggink D, Kongchanagul A, Moran TM, Palese P. 2012. A pan-H1 anti-hemagglutinin monoclonal antibody with potent broad-spectrum efficacy in vivo. J. Virol. 86: 6179-6188.

25. Wohlbold TJ, Nachbagauer R, Margine I, Tan GS, Hirsh A, Krammer F. 2015. Vaccination with soluble headless hemagglutinin protects mice from challenge with divergent influenza viruses. Vaccine 33: 3314-3321.

26. Nabel GJ, Fauci AS. 2010. Induction of unnatural immunity: prospects for a broadly protective universal influenza vaccine. Nat. Med. 16: $1389-1391$

27. Jegaskanda S, Job ER, Kramski M, Laurie K, Isitman G, de Rose R, et al. 2013. Cross-reactive influenza-specific antibody-dependent cellular cytotoxicity antibodies in the absence of neutralizing antibodies. J. Immunol. 190: 1837-1848.

28. Vemula SV, Sayedahmed EE, Sambhara S, Mittal SK. 2017. Vaccine approaches conferring cross-protection against influenza viruses. Expert. Rev. Vaccines 16: 1141-1154.

29. Neirynck S, Deroo T, Saelens X, Vanlandschoot P, Jou WM, Fiers W. 1999. A universal influenza A vaccine based on the extracellular domain of the M2 protein. Nat. Med. 5: 1157-1163.

30. Frace AM, Klimov AI, Rowe T, Black RA, Katz JM. 1999. Modified M2 proteins produce heterotypic immunity against influenza A virus. Vaccine 17: 2237-2244

31. Slepushkin VA, Katz JM, Black RA, Gamble WC, Rota PA, Cox NJ. 1995. Protection of mice against influenza A virus challenge by vaccination with baculovirus-expressed M2 protein. Vaccine 13: 1399-1402.

32. Tutykhina I, Esmagambetov I, Bagaev A, Pichugin A, Lysenko A, Shcherbinin D, et al. 2018. Vaccination potential of B and T epitope-enriched NP and M2 against Influenza A viruses from different clades and hosts. PLoS One 13: e0191574.

33. Jameson J, Cruz J, Terajima M, Ennis FA. 1999. Human CD8+ and CD4+ T lymphocyte memory to influenza A viruses of swine and avian species. J. Immunol. 162: 7578-7583.

34. Gianfrani C, Oseroff C, Sidney J, Chesnut RW, Sette A. 2000. Human memory CTL response specific for influenza A virus is broad and multispecific. Hum. Immunol. 61: 438-452. 
35. Canaday DH, Gehring A, Leonard EG, Eilertson B, Schreiber JR, Harding CV, et al. 2003. T-cell hybridomas from HLA-transgenic mice as tools for analysis of human antigen processing. J. Immunol. Methods 281: 129-142.

36. Misplon JA, Lo CY, Gabbard JD, Tompkins SM, Epstein SL. 2010. Genetic control of immune responses to influenza A matrix 2 protein (M2). Vaccine 28: 5817-5827.

37. Mezhenskaya D, Isakova-Sivak I, Rudenko L. 2019. M2e-based universal influenza vaccines: a historical overview and new approaches to development. J. Biomed. Sci. 26: 76.

38. Grebe KM, Yewdell JW, Bennink JR. 2008. Heterosubtypic immunity to influenza A virus: where do we stand? Microbes Infect. 10: 1024-1029.

39. Rimmelzwaan GF, Fouchier RA, Osterhaus AD. 2007. Influenza virus-specific cytotoxic T lymphocytes: a correlate of protection and a basis for vaccine development. Curr. Opin. Biotechnol. 18: 529-536.

40. Zheng M, Luo J, Chen Z. 2014. Development of universal influenza vaccines based on influenza virus M and NP genes. Infection 42: 251-262.

41. Lee SY, Kang JO, Chang J. 2019. Nucleoprotein vaccine induces cross-protective cytotoxic T lymphocytes against both lineages of influenza B virus. Clin. Exp. Vaccine Res. 8: 54-63.

42. Epstein SL, Kong WP, Misplon JA, Lo CY, Tumpey TM, Xu L, et al. 2005. Protection against multiple influenza A subtypes by vaccination with highly conserved nucleoprotein. Vaccine 23: 5404-5410.

43. Macleod MK, David A, Jin N, Noges L, Wang J, Kappler JW, et al. 2013. Influenza nucleoprotein delivered with aluminium salts protects mice from an influenza A virus that expresses an altered nucleoprotein sequence. PLoS One 8: e61775.

44. Tsybalova LM, Stepanova LA, Shuklina MA, Mardanova ES, Kotlyarov RY, Potapchuk MV, et al. 2018. Combination of M2e peptide with stalk HA epitopes of influenza A virus enhances protective properties of recombinant vaccine. PLoS One 13: e0201429.

45. Stepanova LA, Mardanova ES, Shuklina MA, Blokhina EA, Kotlyarov RY, Potapchuk MV, et al. 2018. Flagellin-fused protein targeting M2e and HA2 induces potent humoral and T-cell responses and protects mice against various influenza viruses a subtypes. J. Biomed. Sci. 25: 33.

46. Kim YJ, Lee YT, Kim MC, Lee YN, Kim KH, Ko EJ, et al. 2017. Cross-protective efficacy of influenza virus M2e containing virus-like particles is superior to hemagglutinin vaccines and variable depending on the genetic backgrounds of mice. Front. Immunol. 8: 1730.

47. Nguyen QT, Kwak C, Lee WS, Kim J, Jeong J, Sung MH, et al. 2019. Poly-gamma-Glutamic acid complexed with alum induces crossprotective immunity of pandemic H1N1 vaccine. Front. Immunol. 10: 1604.

48. Yang J, Shim SM, Nguyen TQ, Kim EH, Kim K, Lim YT, et al. 2017. Poly-gamma-glutamic acid/chitosan nanogel greatly enhances the efficacy and heterosubtypic cross-reactivity of H1N1 pandemic influenza vaccine. Sci. Rep. 7: 44839.

49. Reed LJ, Muench H. 1938. A simple method of estimating fifty percent endpoints. Am. J. Epidemiol. 27: 493-497.

50. Yang M, Berhane Y, Salo T, Li M, Hole K, Clavijo A. 2008. Development and application of monoclonal antibodies against avian influenza virus nucleoprotein. J. Virol. Methods 147: 265-274.

51. Kim MC, Song JM, O E, Kwon YM, Lee YJ, Compans RW, et al. 2013. Virus-like particles containing multiple M2 extracellular domains confer improved cross-protection against various subtypes of influenza virus. Mol. Ther. 21: 485-492.

52. Asthagiri Arunkumar G, Ioannou A, Wohlbold TJ, Meade P, Aslam S, Amanat F, et al. 2019. Broadly cross-reactive, nonneutralizing antibodies against influenza B Virus hemagglutinin demonstrate effector function-dependent protection against lethal viral challenge in mice. J Virol. 93: e01696-18.

53. Park SJ, Si YJ, Kim J, Song MS, Kim SM, Kim EH, et al. 2016. Cross-protective efficacies of highly-pathogenic avian influenza H5N1 vaccines against a recent $\mathrm{H} 5 \mathrm{~N} 8$ virus. Virology 498: 36-43.

54. Jegaskanda S, Weinfurter JT, Friedrich TC, Kent SJ. 2013. Antibody-dependent cellular cytotoxicity is associated with control of pandemic H1N1 influenza virus infection of macaques. J. Virol. 87: 5512-5522.

55. Wang TT, Tan GS, Hai R, Pica N, Ngai L, Ekiert DC, et al. 2010. Vaccination with a synthetic peptide from the influenza virus hemagglutinin provides protection against distinct viral subtypes. Proc. Natl. Acad. Sci. USA 107: 18979-18984.

56. DiLillo DJ, Tan GS, Palese P, Ravetch JV. 2014. Broadly neutralizing hemagglutinin stalk-specific antibodies require FcgammaR interactions for protection against influenza virus in vivo. Nat. Med. 20: 143-151.

57. Black RA, Rota PA, Gorodkova N, Klenk HD, Kendal AP. 1993. Antibody response to the M2 protein of influenza A virus expressed in insect cells. J. Gen. Virol. 74 (Pt 1): 143-146.

58. Feng J, Zhang M, Mozdzanowska K, Zharikova D, Hoff H, Wunner W, et al. 2006. Influenza A virus infection engenders a poor antibody response against the ectodomain of matrix protein 2. Virol. J. 3: 102.

59. Liu W, Li H, Chen YH. 2003. N-terminus of M2 protein could induce antibodies with inhibitory activity against influenza virus replication. FEMS Immunol. Med. Microbiol. 35: 141-146.

60. De Filette M, Ramne A, Birkett A, Lycke N, Lowenadler B, Min Jou W, et al. 2006. The universal influenza vaccine M2e-HBc administered intranasally in combination with the adjuvant CTA1-DD provides complete protection. Vaccine 24: 544-551.

61. Yang P, Wang W, Gu H, Li Z, Zhang K, Wang Z, et al. 2014. Protection against influenza H7N9 virus challenge with a recombinant NP-M1-HSP60 protein vaccine construct in BALB/c mice. Antiviral Res. 111: 1-7.

62. Ameghi A, Pilehvar-Soltanahmadi Y, Baradaran B, Barzegar A, Taghizadeh M, Zarghami N, et al. 2016. Protective immunity against homologous and heterologous influenza virus lethal challenge by immunization with new recombinant chimeric HA2-M2e fusion protein in BALB/C mice. Viral. Immunol. 29: 228-234.

63. Smalls-Mantey A, Doria-Rose N, Klein R, Patamawenu A, Migueles SA, Ko SY, et al. 2012. Antibody-dependent cellular cytotoxicity against primary HIV-infected CD4+ T cells is directly associated with the magnitude of surface IgG binding. J. Virol. 86: 8672-8680.

64. Lai J, Choo JAL, Tan WJ, Too CT, Oo MZ, Suter MA, et al. 2017. TCR-like antibodies mediate complement and antibody-dependent cellular cytotoxicity against Epstein-Barr virus-transformed B lymphoblastoid cells expressing different HLA-A*02 microvariants. Sci. Rep. 7: 9923.

65. He W, Tan GS, Mullarkey CE, Lee AJ, Lam MM, Krammer F, et al. 2016. Epitope specificity plays a critical role in regulating antibodydependent cell-mediated cytotoxicity against influenza A virus. Proc. Natl. Acad. Sci. USA 113: 11931-11936.

66. Allan W, Tabi Z, Cleary A, Doherty PC. 1990. Cellular events in the lymph node and lung of mice with influenza. Consequences of depleting CD4+ T cells. J. Immunol. 144: 3980-3986.

67. Doherty PC, Topham DJ, Tripp RA, Cardin RD, Brooks JW, Stevenson PG. 1997. Effector CD4+ and CD8+ T-cell mechanisms in the control of respiratory virus infections. Immunol. Rev. 159: 105-117.

68. Eichelberger MC, Wang ML, Allan W, Webster RG, Doherty PC. 1991. Influenza virus RNA in the lung and lymphoid tissue of immunologically intact and CD4-depleted mice. J. Gen. Virol. 72 (Pt 7): 1695-1698.

69. Bridges CB, Fukuda K, Uyeki TM, Cox NJ, Singleton JA, Centers for disease C, et al. 2002. Prevention and control of influenza. Recommendations of the advisory committee on immunization practices (ACIP). MMWR Recomm. Rep. 51: 1-34.

70. Simonsen L, Clarke MJ, Schonberger LB, Arden NH, Cox NJ, Fukuda K. 1998. Pandemic versus epidemic influenza mortality: a pattern of changing age distribution. J. Infect. Dis. 178: 53-60.

71. Vesikari T, Pellegrini M, Karvonen A, Groth N, Borkowski A, O'Hagan DT, et al. 2009. Enhanced immunogenicity of seasonal influenza vaccines in young children using MF59 adjuvant. Pediatr Infect. Dis. J. 28: 563-571.

72. McElhaney JE, Beran J, Devaster JM, Esen M, Launay O, Leroux-Roels G, et al. 2013. AS03-adjuvanted versus non-adjuvanted inactivated trivalent influenza vaccine against seasonal influenza in elderly people: a phase 3 randomised trial. Lancet Infect. Dis. 13: 485-496. 